\title{
Article \\ COVID-19 Psychological Impact on Health Care Workers in Saudi Arabia
}

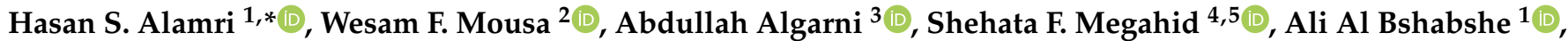 \\ Nada N. Alshehri ${ }^{1}{ }^{\complement}$, Awad Alsamghan ${ }^{4}$, Abdullah Alsabaani ${ }^{4}{ }^{(0}$, Rasha T. Mirdad ${ }^{6}$, Asrar M. Alshahrani ${ }^{7}$, \\ Alya A. Gadah ${ }^{8}$ and Almah A. Alshehri ${ }^{3}$
}

\section{check for} updates

Citation: Alamri, H.S.; Mousa, W.F.; Algarni, A.; Megahid, S.F.; Al Bshabshe, A.; Alshehri, N.N.; Alsamghan, A.; Alsabaani, A.; Mirdad, R.T.; Alshahrani, A.M.; et al. COVID-19 Psychological Impact on Health Care Workers in Saudi Arabia Int. J. Environ. Res. Public Health 2021, 18, 6076. https://doi.org/10.3390/ ijerph18116076

Academic Editor: Paul B. Tchounwou

Received: 10 May 2021

Accepted: 2 June 2021

Published: 4 June 2021

Publisher's Note: MDPI stays neutral with regard to jurisdictional claims in published maps and institutional affiliations.

Copyright: (c) 2021 by the authors Licensee MDPI, Basel, Switzerland. This article is an open access article distributed under the terms and conditions of the Creative Commons Attribution (CC BY) license (https:// creativecommons.org/licenses/by/ $4.0 /)$
1 Department of Medicine, College of Medicine, King Khalid University, Abha 62527, Saudi Arabia; albshabshe@yahoo.com (A.A.B.);dr_nada@hotmail.co.uk (N.N.A.)

2 College of Medicine, University of Tanta, Tanta 31512, Egypt; wesammousa@hotmail.com

3 Ministry of Health, Abha 62523, Saudi Arabia; abaid1406@gmail.com (A.A.); almaha.alshehri@hotmail.com (A.A.A.)

4 Department of Family and Community Medicine, College of Medicine, King Khalid University, Abha 61421, Saudi Arabia; shehatafarag@yahoo.com (S.F.M.); asoman@kku.edu.sa (A.A.); dr.alsabaani@hotmail.com (A.A.)

5 Biostatistics Department, High Institute of Public Health, Alexandria University, 65 Garidet St., El Horeya Rd. El Shatby, Alexandria 21526, Egypt

6 Armed Forces Hospital Southern Region, Khamis Mushait 62413, Saudi Arabia; Rashamirdad1995@hotmail.com

7 King Fahad Medical City, Riyadh 11564, Saudi Arabia; Asraralshahrani@hotmail.com

8 King Abdulaziz Medical City, Riyadh 14611, Saudi Arabia; Aliahgd@hotmail.com

* Correspondence: hsalamri@kku.edu.sa

Abstract: Objective: Little is known about the impact of Coronavirus (COVID-19) among the health care workers in Saudi Arabia. Therefore, the present study aimed to assess the psychological impact of COVID-19 among the health care workers. Methods: A cross-sectional survey was conducted from May till mid-July among 389 health care workers from government and private hospitals in Saudi Arabia. Data was collected using a pre-structured online questionnaire that measured adverse psychological outcomes, including the Patient Health Questionnaire-9 (PHQ-9) scale and the Generalized Anxiety Disorder 7-item (GAD-7) scale. The Pearson chi-square test was used to assess the distribution of depression and anxiety among health care workers. Results: A high level of anxiety was recorded among the health care workers, and $69.3 \%$ of health care workers below the age of 40 were found to have depression. There was a significant increase in depression among staff with chronic health problems $(72.1 \%$ vs. $61.9 \% ; p=0.048)$. High anxiety levels were detected among young staff compared to others $(68.7 \%$ vs. $43.8 \% ; p=0.001)$. Moreover, $82.1 \%$ of the female staff were anxious, as compared to $55.6 \%$ of the males $(p=0.001)$. Conclusions: We found increased prevalence of adverse psychological outcomes among the health care workers in Saudi Arabia during the outbreak of COVID-19. Therefore, there is a need for proper screening and development of corresponding preventive measures to decrease the adverse psychological outcomes.

Keywords: coronavirus; anxiety; depression; observational descriptive study

\section{Introduction}

The outbreak of Coronavirus (COVID-19) was declared a pandemic on 1 March 2020 by the World Health Organization [1]. In the following months, quarantine and travel restrictions were imposed in most countries across the world. It is known that there are adverse psychological outcomes associated with an outbreak of infectious disease. The risk of mental diseases like anxiety, post-traumatic stress, depression, and thought disorders increases as the result of containment measures such as self-quarantine and social distancing [2]. Medical workers, in comparison to the public are at a higher risk 
of experiencing negative psychological effects following a disaster, pandemic situation, or an emergency. Previous studies reported severe emotional stress among the health care workers (HCWs) following the outbreak of infectious diseases [3-5]. This includes the severe acute respiratory syndrome (SARS) epidemic in 2003, Ebola virus in 2014, and Middle East Respiratory syndrome (MERS) outbreak in 2015 [6].

There are different factors used to determine the adverse psychological outcomes among the HCWs during infectious disease outbreaks, which are followed with increased mortality rate, uncertain and long quarantine, fear, discrimination, inadequate medical supplies, and stigma [2,7]. Previous studies have shown that the most common predictors of acute post-traumatic stress, chronic post-traumatic stress, and other mental conditions are both an increase in negative coping strategies and, simultaneously, a decrease in support to HCWs $[8,9]$. There is significant association between the adoption of support HCWs gain from others and their psychological status during the disease outbreak [4]. Another important factor was noted in a study by Bhagavathula et al. [10], which highlighted that the mental health of health workers can be impacted by the lack of knowledge about COVID-19 infection potential and even the widespread misinformation (social media dissemination). The authors discussed the important question of how information is managed, where improving the dissemination of scientific and authentic content can help frontline HCWs in times of public health emergency. There is a significant association between the adoption of support HCWs gain from others and their psychological status during the disease outbreak [4]. Previous studies have shown that the most common predictors of acute post-traumatic stress, chronic post-traumatic stress, and other mental conditions are an increase in the negative coping strategies and a decrease in support to the HCWs $[8,9]$.

The chances of adverse psychological outcomes among HCWs have increased considering the magnitude of COVID-19, especially among the workers performing front line duties. One of the previous studies by Lancee et al. [11] reported a high level of anxiety, post-traumatic stress, emotional stress, and depression among the medical HCWs during, as well as after, the outbreak of infectious diseases. Similarly, a study conducted in Italy revealed that $24.7 \%$ of HCWs had depression symptoms, $19.8 \%$ had anxiety symptoms, $8.27 \%$ had insomnia, $21.9 \%$ had perceived stress symptoms, and $49.38 \%$ endorsed PTSS [12]. Bai et al. [13] conducted a study in Taiwan and reported that approximately $5 \%$ of the HCWs suffered from acute stress disorder. The symptoms of PTSS and acute stress disorder are the same. Therefore, diagnosis of acute stress disorder 3 days to 1 month after trauma is considered a good predictor of PTSS [14]. Ranieri et al.'s [15] findings were obtained in the short and long term after an Italian COVID-19 outbreak. They measured its short-time mental health impact for HCWs, highlighting anxiety as an early reaction for emotional distress and a high risk for post-traumatic stress disorders. The personality dimensions did not mediate the emotional distress as well as probable risk for post-traumatic stress symptoms. The emotional distress was protracted overtime (after 6 months) but in the long term, personality traits were a factor in subjective stress.

There are only few studies that have investigated the psychological impact of the COVID-19 pandemic on the HCWs among the countries that were strongly hit by this infection, like China, United States, India, and Saudi Arabia. Moreover, none of the studies have majorly focused on Saudi Arabian HCWs and assessed the impact of COVID-19 on their psychological well-being. It should be possible to develop and provide effective interventions and treatment to the Saudi population by understanding the psychological outcomes and the related mechanisms among the HCWs during infectious disease outbreaks to improve their psychological well-being. Therefore, the present study aimed to assess the presence of anxiety, depression, and related psychological outcomes among the HCWs following the COVID-19 pandemic. This would help in better understanding the psychological suffering of HCWs and help in developing interventions for alleviating psychological stress among the Saudi population. 


\section{Materials and Methods}

\subsection{Study Design and Sample}

A cross sectional survey was conducted, including 389 accessible HCWs during the COVID-19 pandemic in the governmental and private hospitals and primary health care centers in Saudi Arabia.

Tools used to assess mental and psychological health were the Arabic versions of the Patient Health Questionnaire-9 (PHQ-9) scale and the Generalized Anxiety Disorder 7-item (GAD-7) scale [16]. The PHQ-9 is the depression module, which scores each of the nine DSM-IV criteria as " 0 " (not at all) to " 3 " (nearly every day) [17]. It has been validated for use in primary care [18] and used to monitor the severity of depression. The total score of PHQ-9 ranges from 0 to 27; scores " $0-4$ " mean no depression, scores " $5-9$ " mean mild depression, scores "10-14" mean moderate depression, scores "15-19" mean moderately severe depression, and scores "20-27" mean severe depression. The GAD-7 is the anxiety module and scores of 5,10, and 15 are taken as the cut-off points for mild, moderate, and severe anxiety, respectively $[19,20]$.

The data were collected using a pre-structured online questionnaire developed by the researchers after an intensive literature review and expert consultation as a panel of 3 consultants reviewed the items independently. Any discrepancy regarding any item was resolved by consensus at first, then by voting. After agreeing on the final questionnaire format, it was raised online using social media platforms and sent to all accessible staff using a snowball sampling method. The survey remained on the social media platforms from May till mid July 2020. The questionnaire included HCW's personal data, academic position, qualification, years of experience, chronic health problems, and setting. The amount of contact with COVID-19 cases and history of getting COVID-19 infection were also considered.

Before starting the survey, the participants were informed about the aims of the study and the protection of personal data. They were asked to confirm their informed consent to participate. The study was conducted in accordance with the Declaration of Helsinki, and it was approved by the King Khalid University Research Ethics Committee (Approval Number: ECM\#2020-237-HAPO-06-B-001) and the Research Ethical Committee at General Directorate of Health Affairs, Aseer Region, Saudia Arabia.

A pilot study of $20 \mathrm{HCW}$ s was done to assess PHQ-9 and GAD-7 applicability and reliability. Both tools showed $\alpha$-Cronbach's of 0.85 and 0.77 , respectively.

\subsection{Data Analysis}

All participants' responses were downloaded and filtered for missing or incorrect data after online submission. After this, the data were extracted, revised, coded, and fed to statistical software IBM SPSS version 22 (SPSS, Inc., Chicago, IL, USA). All statistical analysis was done using two tailed tests. A $p$ value of less than 0.05 was statistically significant. Regarding PHQ-9 and GAD-7 scales, all discrete scores were summed and categorized based on the reference section cut off points. Descriptive analysis based on frequency and percent distribution was done for all variables, including demographic data, work data, PHQ-9 and GAD-7 scales. Cross tabulation was used to assess the distribution of HCW's depression and anxiety status according to their personal and work-related data. Relations were tested using the Pearson chi-square test.

\section{Results}

The study included $389 \mathrm{HCWs}$ from different regions of Saudi Arabia with ages ranging between 20 and 65 years and a mean age of $28.6 \pm 10.4$ years. The majority of HCWs who completed the questionnaire were males (68.4\%) and Saudi (92.8\%). In regards to marital status, $69.4 \%$ of the responding staff were married and $56.1 \%$ had $1-3$ children. As for qualification, $39.3 \%$ had a bachelor's degree and $42.7 \%$ had post graduate degrees (Master, Fellowship, Board, or PhD). Around 71.5\% of the HCWs had no chronic health 
problems, while allergic or autoimmune problems were reported in $8.7 \%$, diabetes mellitus in $5.9 \%$, and hypertension in $5.4 \%$ HCWs (Table 1 ).

Table 1. Personal data of respondent HCWs, Saudi Arabia, 2020.

\begin{tabular}{|c|c|c|c|}
\hline \multicolumn{2}{|c|}{ Personal Data } & \multirow{2}{*}{$\begin{array}{l}\text { No } \\
266\end{array}$} & \multirow{2}{*}{$\begin{array}{c}\% \\
68.4 \%\end{array}$} \\
\hline Gender & Male & & \\
\hline & Female & 123 & $31.6 \%$ \\
\hline \multirow{5}{*}{ Age in years } & $20-$ & 132 & $33.9 \%$ \\
\hline & $30-$ & 184 & $47.3 \%$ \\
\hline & $40-$ & 45 & $11.6 \%$ \\
\hline & $50-$ & 18 & $4.6 \%$ \\
\hline & $60+$ & 10 & $2.6 \%$ \\
\hline \multirow{3}{*}{ Marital status } & Single & 109 & $28.0 \%$ \\
\hline & Married & 270 & $69.4 \%$ \\
\hline & Divorced/widow & 10 & $2.6 \%$ \\
\hline \multirow{4}{*}{ Number of children } & None & 38 & $13.6 \%$ \\
\hline & $1-3$ & 157 & $56.1 \%$ \\
\hline & $4-5$ & 63 & $22.5 \%$ \\
\hline & $6+$ & 22 & $7.9 \%$ \\
\hline \multirow{8}{*}{ Qualification } & High school & 5 & $1.3 \%$ \\
\hline & Bachelor & 153 & $39.3 \%$ \\
\hline & Diploma & 65 & $16.7 \%$ \\
\hline & Master & 33 & $8.5 \%$ \\
\hline & Board & 86 & $22.1 \%$ \\
\hline & Fellowship & 40 & $10.3 \%$ \\
\hline & $\mathrm{PhD}$ & 7 & $1.8 \%$ \\
\hline & None & 278 & $71.5 \%$ \\
\hline \multirow{7}{*}{$\begin{array}{l}\text { Chronic health } \\
\text { problems }\end{array}$} & $\mathrm{DM}$ & 23 & $5.9 \%$ \\
\hline & HTN under treatment & 21 & $5.4 \%$ \\
\hline & $\begin{array}{l}\text { Mental health } \\
\text { problems }\end{array}$ & 16 & $4.1 \%$ \\
\hline & Cardiac problems & 10 & $2.6 \%$ \\
\hline & $\begin{array}{c}\text { Allergic/autoimmune } \\
\text { problems }\end{array}$ & 34 & $8.7 \%$ \\
\hline & $\begin{array}{c}\text { Chronic immune } \\
\text { deficiency }\end{array}$ & 13 & $3.3 \%$ \\
\hline & Others & 21 & $5.4 \%$ \\
\hline
\end{tabular}

Table 2 demonstrates work data for the HCWs, which shows that $47 \%$ of the workers were physicians, $22.1 \%$ were technicians, and $17 \%$ were nurses. In regards to years of experience, $43.4 \%$ had been working for 5-14 years, while $36.5 \%$ had worked for less than 5 years. Most HCWs worked in general hospitals $(47.8 \%)$, followed by primary health care centers $(23.7 \%)$, and specialist hospitals (19.3\%). Around $47.6 \%$ of the participants were in direct contact with COVID-19 cases (first line) and only 2.6\% had COVID-19 infection. 
Table 2. Work related data of HCWs, Saudi Arabia, 2020.

\begin{tabular}{|c|c|c|c|}
\hline & Work Related Data & No & $\%$ \\
\hline \multirow{6}{*}{ Job } & Social worker & 7 & $1.8 \%$ \\
\hline & Administrative & 33 & $8.5 \%$ \\
\hline & Technician & 86 & $22.1 \%$ \\
\hline & Nursing & 66 & $17.0 \%$ \\
\hline & Dentist & 14 & $3.6 \%$ \\
\hline & Physician & 183 & $47.0 \%$ \\
\hline \multirow{4}{*}{ Experience years } & $<5$ years & 142 & $36.5 \%$ \\
\hline & $5-14$ & 169 & $43.4 \%$ \\
\hline & $15-24$ & 57 & $14.7 \%$ \\
\hline & $25+$ & 21 & $5.4 \%$ \\
\hline \multirow{4}{*}{ Work setting } & Primary health care center & 92 & $23.7 \%$ \\
\hline & Specialist hospital & 75 & $19.3 \%$ \\
\hline & University hospital & 36 & $9.3 \%$ \\
\hline & General hospital & 186 & $47.8 \%$ \\
\hline \multirow{2}{*}{$\begin{array}{l}\text { Degree of contact } \\
\text { with COVID-19 cases }\end{array}$} & First line: direct contact with COVID cases & 185 & $47.6 \%$ \\
\hline & Second line: department with no COVID cases & 204 & $52.4 \%$ \\
\hline \multirow{2}{*}{$\begin{array}{l}\text { Diagnosed to have } \\
\text { Covid-19 before }\end{array}$} & Yes & 10 & $2.6 \%$ \\
\hline & No & 379 & $97.4 \%$ \\
\hline
\end{tabular}

Regarding PHQ9 items considering depression among the study participants, 73.3\% of the HCWs felt tired to different degrees with little energy, followed by little interest or pleasure in doing things $(67.6 \%)$, trouble falling or staying asleep, or sleeping too much (67.1\%). For the global assessment question that checked how difficult these problems made it for the person to work, the answer was $44.5 \%, 37.8 \%, 14.4 \%$, and $3.3 \%$ for not difficult at all, somewhat difficult, very difficult, and extremely difficult, respectively (Table 3). In total, $35.2 \%$ of the HCWs had no detectable depression based on the PHQ9 scale, while mild depression was detected in $27.5 \%$, moderate depression in $18.8 \%$, moderately severe depression in $11.3 \%$, and severe depression in $7.2 \%$ of the HCWs (Table 3 ).

Table 3. Depression among HCWs in Saudi Arabia during the Covid-19 pandemic.

\begin{tabular}{ccccc}
\hline PHQ9 Items & $\begin{array}{c}\text { Not at } \\
\text { All }\end{array}$ & $\begin{array}{c}\text { Several } \\
\text { Days }\end{array}$ & $\begin{array}{c}\text { More Than } \\
\text { Half the Days }\end{array}$ & $\begin{array}{c}\text { Nearly } \\
\text { Every Day }\end{array}$ \\
\cline { 2 - 5 } & No (\%) & No (\%) & No (\%) & No (\%) \\
\hline $\begin{array}{c}\text { Little interest or pleasure in } \\
\text { doing things }\end{array}$ & $126(32.4)$ & $131(33.7)$ & $64(16.5)$ & $68(17.5)$ \\
\hline $\begin{array}{c}\text { Feeling down, depressed, } \\
\text { or hopeless }\end{array}$ & $129(33.2)$ & $137(35.2)$ & $64(16.5)$ & $59(15.2)$ \\
\hline $\begin{array}{c}\text { Trouble falling or staying asleep, or } \\
\text { sleeping too much }\end{array}$ & $128(32.9)$ & $123(31.6)$ & $56(14.4)$ & $82(21.1)$ \\
\hline $\begin{array}{c}\text { Feeling tired or having little energy } \\
\text { Poor appetite or overeating }\end{array}$ & $104(26.7)$ & $162(41.6)$ & $50(12.9)$ & $73(18.8)$ \\
\hline $\begin{array}{c}\text { Feeling bad about yourself or that } \\
\text { you are a failure or have let } \\
\text { yourself or your family down }\end{array}$ & $234(60.2)$ & $92(23.7)$ & $32(8.2)$ & $60(15.4)$ \\
\hline
\end{tabular}


Table 3. Cont.

\begin{tabular}{|c|c|c|c|c|}
\hline \multirow[t]{2}{*}{ PHQ9 Items } & $\begin{array}{c}\text { Not at } \\
\text { All }\end{array}$ & $\begin{array}{c}\text { Several } \\
\text { Days }\end{array}$ & $\begin{array}{c}\text { More Than } \\
\text { Half the Days }\end{array}$ & $\begin{array}{c}\text { Nearly } \\
\text { Every Day }\end{array}$ \\
\hline & No $(\%)$ & No $(\%)$ & No $(\%)$ & No $(\%)$ \\
\hline $\begin{array}{l}\text { Trouble concentrating on things, } \\
\text { such as reading the newspaper or } \\
\text { watching television }\end{array}$ & $195(50.1)$ & $101(26.0)$ & 45 (11.6) & $48(12.3)$ \\
\hline $\begin{array}{l}\text { Moving or speaking so slowly that } \\
\text { other people could have noticed? } \\
\text { Or the opposite-being so fidgety } \\
\text { or restless that you have been } \\
\text { moving around a lot more } \\
\text { than usual }\end{array}$ & $222(57.1)$ & $98(25.2)$ & $44(11.3)$ & $25(6.4)$ \\
\hline $\begin{array}{c}\text { Thoughts that you would be better } \\
\text { off dead or of hurting yourself in } \\
\text { some way }\end{array}$ & $337(86.6)$ & $30(7.7)$ & $6(1.5)$ & $16(4.1)$ \\
\hline \multirow{2}{*}{$\begin{array}{l}\text { If you checked off any problems, } \\
\text { how difficult have these problems } \\
\text { made it for you to do your work, } \\
\text { take care of things at home, or get } \\
\text { along with other people }\end{array}$} & $\begin{array}{l}\text { Not } \\
\text { difficult } \\
\text { at all }\end{array}$ & $\begin{array}{l}\text { Somewhat } \\
\text { difficult }\end{array}$ & Very difficult & $\begin{array}{l}\text { Extremely } \\
\text { difficult }\end{array}$ \\
\hline & $173(44.5)$ & $147(37.8)$ & $56(14.4)$ & $13(3.3)$ \\
\hline \multirow[t]{2}{*}{ Depression level } & $\begin{array}{l}\text { Mild de- } \\
\text { pression }\end{array}$ & $\begin{array}{c}\text { Moderate } \\
\text { depression }\end{array}$ & $\begin{array}{l}\text { Moderately } \\
\text { severe }\end{array}$ & $\begin{array}{c}\text { Severe } \\
\text { depression }\end{array}$ \\
\hline & $107(27.5)$ & $73(18.8)$ & $44(11.3)$ & $28(7.2)$ \\
\hline
\end{tabular}

Regarding GAD7 items, Table 4 shows the level of anxiety disorder among the study participants. It shows that $76.1 \%$ of the HCWs felt nervous/anxious, $74.8 \%$ worried too much about different things, $72 \%$ experienced trouble relaxing, $69.9 \%$ were easily annoyed or irritable, and $63.3 \%$ were not able to stop or control worrying. For the global assessment question that checked how difficult these were for HCWs, the answer was $41.9 \%, 37.8 \%$, $13.9 \%$, and $6.4 \%$ for not difficult at all, somewhat difficult, very difficult and extremely difficult, respectively. In total, $36 \%$ of the respondent HCWs had no detectable anxiety, while $32.9 \%$ had a mild anxiety level, $13.6 \%$ had a moderate anxiety level, and $17.5 \%$ had a severe anxiety level.

Table 5 illustrates the distribution of depression and anxiety among health care staff according to their personal data. Depression was detected in $69.3 \%$ of HCWs below the age of 40 years as compared to $45.2 \%$ of those aged 40 or more $(p=0.001)$. In addition, $79.7 \%$ of the female workers had detectable depression in comparison to $57.9 \%$ of the males $(p=0.001)$. Depression was significantly higher among staff with chronic health problems (72.1\% vs. $61.9 \% ; p=0.048)$. It was also significantly higher among new staff with less experience than those with high experience $(78.2 \%$ and $38.1 \%$, respectively; $p=0.001)$. All HCWs who had COVID-19 infection were depressed as compared to $63.9 \%$ of others $(p=0.018)$. Anxiety was significantly higher among young staff than others $(68.7 \%$ vs. $43.8 \% ; p=0.001)$, and $82.1 \%$ of the female staff were anxious, as compared to $55.6 \%$ of males $(p=0.001)$.

HCWs who had chronic health problems showed a higher anxiety rate than others ( $71.2 \%$ vs. $61.2 \%$, respectively; $p=0.049$ ). Anxiety was also detected in $68.8 \%$ of the medical staff compared to $54 \%$ of the paramedical group (administrative, technician, and social workers). Moreover, $75.1 \%$ of the staff who were in direct contact with COVID-19 cases had detectable anxiety compared to $53.9 \%$ of those who were on the second line $(p=0.001)$. Anxiety was detected in $70 \%$ of the previously infected staff as compared to $63.9 \%$ of those not previously infected. 
Table 4. Anxiety disorder among HCWs in Saudi Arabia during the Covid-19 pandemic.

\begin{tabular}{|c|c|c|c|c|}
\hline \multirow[t]{2}{*}{ GAD7 Items } & $\begin{array}{c}\text { Not at } \\
\text { All }\end{array}$ & $\begin{array}{c}\text { Several } \\
\text { Days }\end{array}$ & $\begin{array}{l}\text { More Than } \\
\text { Half the Days }\end{array}$ & $\begin{array}{c}\text { Nearly } \\
\text { Every Day }\end{array}$ \\
\hline & No $(\%)$ & No $(\%)$ & No $(\%)$ & No (\%) \\
\hline $\begin{array}{l}\text { Feeling nervous, anxious or } \\
\text { on edge }\end{array}$ & 93 (23.9) & $167(42.9)$ & $76(19.5)$ & $53(13.6)$ \\
\hline $\begin{array}{l}\text { Not being able to stop or } \\
\text { control worrying }\end{array}$ & $143(36.8)$ & $131(33.7)$ & $52(13.4)$ & $63(16.2)$ \\
\hline $\begin{array}{l}\text { Worrying too much about } \\
\text { different things }\end{array}$ & $98(25.2)$ & $155(39.8)$ & $70(18.0)$ & $66(17.0)$ \\
\hline Trouble relaxing & $109(28.0)$ & $142(36.5)$ & $77(19.8)$ & $61(15.7)$ \\
\hline $\begin{array}{c}\text { Being so restless that it is hard to } \\
\text { sit still }\end{array}$ & $196(50.4)$ & $105(27.0)$ & $46(11.8)$ & $42(10.8)$ \\
\hline $\begin{array}{l}\text { Becoming easily annoyed } \\
\text { or irritable }\end{array}$ & $117(30.1)$ & $143(36.8)$ & $62(15.9)$ & $67(17.2)$ \\
\hline $\begin{array}{l}\text { Feeling afraid as if something } \\
\text { awful might happen }\end{array}$ & $179(46.0)$ & $116(29.8)$ & $39(10.0)$ & $55(14.1)$ \\
\hline \multirow{2}{*}{$\begin{array}{l}\text { If you checked off any problems, } \\
\text { how difficult have these problems } \\
\text { made it for you to do your work, } \\
\text { take care of things at home, or get } \\
\text { along with other people }\end{array}$} & $\begin{array}{c}\text { Not } \\
\text { difficult } \\
\text { at all }\end{array}$ & $\begin{array}{l}\text { Somewhat } \\
\text { difficult }\end{array}$ & Very difficult & $\begin{array}{l}\text { Extremely } \\
\text { difficult }\end{array}$ \\
\hline & $163(41.9)$ & $147(37.8)$ & $54(13.9)$ & $25(6.4)$ \\
\hline \multirow[t]{2}{*}{ Anxiety level } & $\begin{array}{l}\text { Mild de- } \\
\text { pression }\end{array}$ & $\begin{array}{l}\text { Moderate } \\
\text { depression }\end{array}$ & $\begin{array}{l}\text { Moderately } \\
\text { severe }\end{array}$ & $\begin{array}{c}\text { Severe } \\
\text { depression }\end{array}$ \\
\hline & $140(36.0)$ & $128(32.9)$ & $53(13.6)$ & $68(17.5)$ \\
\hline
\end{tabular}

Table 5. Distribution of depression and anxiety among HCWs according to their personal data.

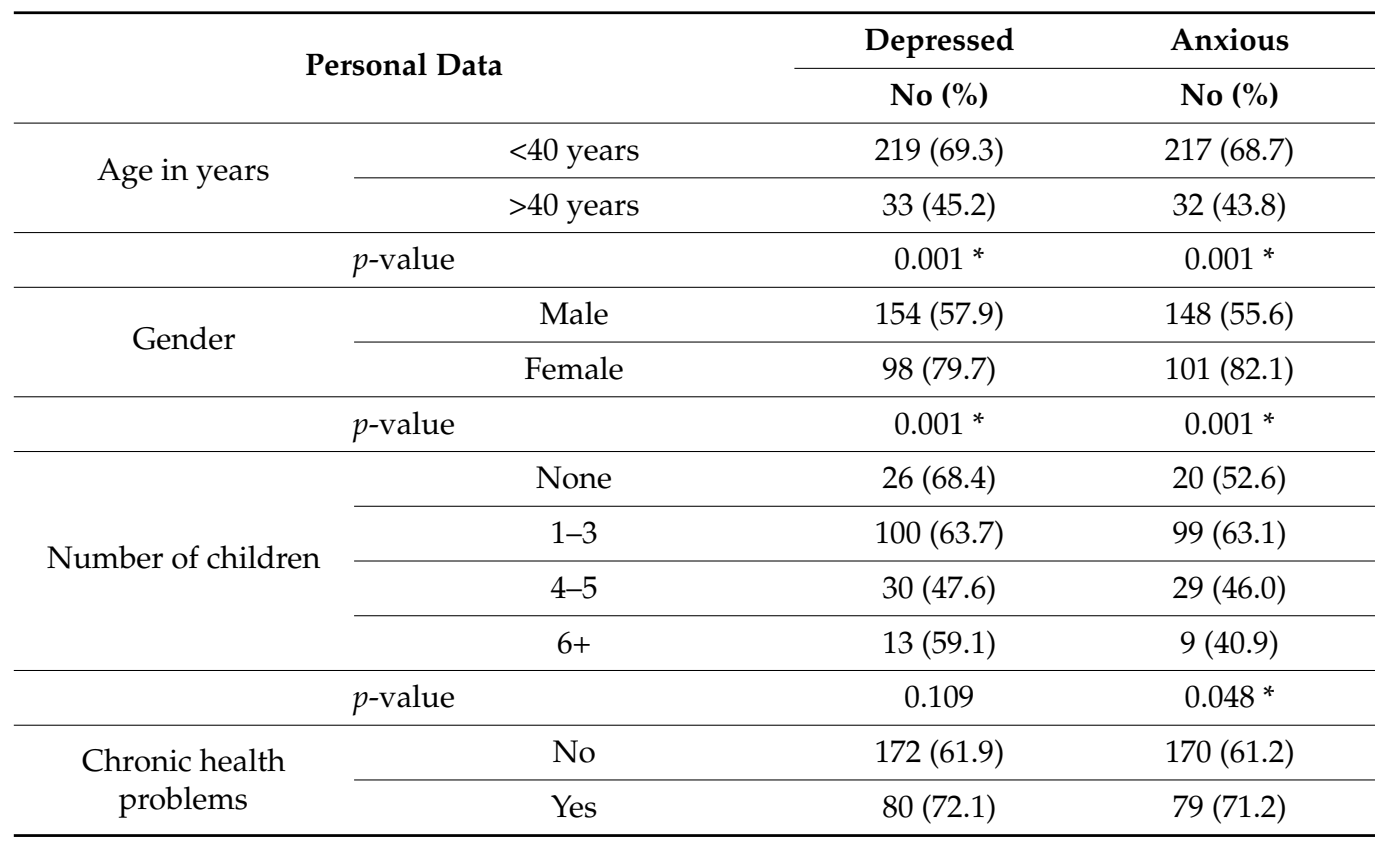


Table 5. Cont.

\begin{tabular}{|c|c|c|c|}
\hline \multirow{2}{*}{\multicolumn{2}{|c|}{ Personal Data }} & Depressed & Anxious \\
\hline & & No $(\%)$ & No $(\%)$ \\
\hline \multicolumn{2}{|r|}{$p$-value } & $0.048^{*}$ & $0.049 *$ \\
\hline \multirow{2}{*}{ Job } & Paramedical & $78(61.9)$ & $68(54.0)$ \\
\hline & Medical & $174(66.2)$ & $181(68.8)$ \\
\hline & $p$-value & 0.411 & $0.004 *$ \\
\hline \multirow{4}{*}{ Experience years } & $<5$ years & $111(78.2)$ & 109 (76.8) \\
\hline & $5-14$ & $102(60.4)$ & $104(61.5)$ \\
\hline & $15-24$ & $31(54.4)$ & $26(45.6)$ \\
\hline & $25+$ & $8(38.1)$ & $10(47.6)$ \\
\hline & $p$-value & 0.001 * & $0.001 *$ \\
\hline \multirow{2}{*}{$\begin{array}{c}\text { Degree of contact } \\
\text { with COVID-19 cases }\end{array}$} & $\begin{array}{l}\text { First line: direct contact with } \\
\text { COVID cases }\end{array}$ & $126(68.1)$ & $139(75.1)$ \\
\hline & $\begin{array}{l}\text { Second line: department } \\
\text { with no COVID cases }\end{array}$ & $126(61.8)$ & $110(53.9)$ \\
\hline \multirow{3}{*}{$\begin{array}{l}\text { Diagnosed to have } \\
\text { Covid-19 before }\end{array}$} & $p$-value & 0.191 & $0.001 *$ \\
\hline & Yes & $10(100.0)$ & $7(70.0)$ \\
\hline & No & $242(63.9)$ & $242(63.9)$ \\
\hline \multicolumn{2}{|r|}{$p$-value } & 0.018 * & 0.689 \\
\hline
\end{tabular}

\section{Discussion}

The aim of this study was to survey the current psychological impact of the Covid19 pandemic among health care professionals in different regions in Saudi Arabia and discuss the different factors that might have contributed to it. Survey findings revealed that psychological stress exists among health care professionals $(p=0.001)$ and the presence of such stress should be consistently highlighted in the literature to reduce the overflowing anxiety and depression among them, improve patient's care, and above all afford a healthy working environment. The results of the present study revealed increased prevalence of anxiety and depression among Saudi HCWs during the COVID-19 outbreak. More than half of the HCWs with chronic health problems showed higher anxiety, as compared to others $(71.2 \%$ vs. $61.2 \%)$. These percentages were higher than post-traumatic stress disorder (1-27\%) during the SARS outbreak in 2003 [21] and the Ebola outbreak during 2014 and 2016 [7]. The proportion of anxiety and depression reported in this study shows that it was higher in Saudi Arabia, as compared to India and Singapore [22].

The results of the present study show lack of knowledge about psychological coping strategies under these sorts of overwhelming conditions. There might be differences in the psychological health of the workers during infectious disease outbreaks because of the capability and infrastructure of the healthcare system. A similar study was conducted among the Chinese HCWs that reported increased prevalence of anxiety, stress, and depression symptoms [23]. This study also indicated the actual psychological status at the beginning of the COVID-19 outbreak in China [23].

It has been shown that post-traumatic disorder can be manifested through symptoms of hyper-arousal, avoidance, and intrusion after experiencing a traumatic event [24]. Few of the previous studies have confirmed that HCWs develop psychological problems such as stress and depression after a traumatic situation $[13,25]$. The HCWs performing front line duties during an infectious disease outbreak are also at higher risk of getting infected, especially if they feel any symptoms $[13,26]$. Moreover, there was also a high risk of transmitting the virus to the families of HCWs because of close contact with them. This 
made the HCWs more distant and stigmatized. One of the previous studies conducted in China reported three dimensions, fear of infection, perceived high risk of their job, and distancing, that were significantly associated with adverse psychological outcomes [6]. The psychological health of HCWs during an infectious disease outbreak can be improved through friendly mass media and a supportive social environment for alleviating perceived threats among the HCWs. There is also a need to provide HCWs with accurate information and psychological counseling to target stigmatization against the frontline HCWs.

The relationship between people and their environment is improved by focusing on problem solving through active coping strategies, which results in positive emotional responses. In a similar context, the results of the present study have demonstrated that providing sufficient social support and promoting active coping strategies helps in decreasing the development of psychological symptoms such as stress, depression, and anxiety. These results are in agreement with previous studies that showed a buffering effect of social support and active coping strategies on negative psychological health of the HCWs [27]. Relieving the emotional distress is the main aim of passive coping strategies as it is associated with worse psychological health like depression, post-traumatic stress, and anxiety symptoms. It has been shown that it is important to reduce post-traumatic stress among the HCWs through passive coping strategies, so that they are well-aware of the pandemic both mentally and materially.

Low percentages of anxiety and depression in our study and the previous studies might be attributed to the fact that health care professionals experience high levels of satisfaction from their roles caring for others [28] and that religious beliefs have supported the positive effects of spirituality on health care professionals [29]. However, the depressed mood or anxiety exhibited in some healthcare professionals is exacerbated by the extraordinary burden of an augmented work load, inadequate personal protective equipment, the fear of developing COVID-19 virus infection with ensuing infection of friends and relatives, and the need to make ethically tough decisions [30,31].

In this study, it was found that female health care staff and individuals with less experience were more likely to develop symptoms of stress and anxiety, as compared to others. It is expected that the increased level of anxiety among the individuals would be because they would have direct access to patient's blood or belonged to lower social economic status. These factors are likely to increase the susceptibility of HCWs to COVID19. No significant differences were detected between nationalities or varying number of children. However, anxiety, but not depression, was significantly higher with a higher number of children, among paramedical staff, and among first line contacts with COVID-19 cases. On the other hand, depression, but not anxiety, was significantly higher among HCWs who were previously diagnosed with COVID-19. Patient care depends heavily on the ability of health care professionals to work in a healthy workplace environment. Thus, we cannot afford to ignore the snowballing anxiety and depression among them [32]. The presence of anxiety/depression among health care professionals as shown in the present study makes the point that the working situation needs to be considered during the COVID-19 pandemic. The recognition of the problem would certainly lead to measures to curb it, although depression/anxiety among workers may be inevitable [33].

The results of the present study indicated more depression and anxiety in those below 40 years of age, females, staff with chronic health problems, new staff with less experience, and previously infected staff. This was similar to the findings reported in frontline medical workers during outbreaks of SARS [21,34]. These findings were also comparable to a metaanalysis of 13 Asian studies that reported a prevalence of $23.2 \%$ for anxiety and $22.8 \%$ for depression in response to COVID-19 in HCWs [30] and to a more recent meta-analysis [26] that found a similar prevalence of $26 \%$ for anxiety and $25 \%$ for depression among HCWs.

This study suggests that considering and focusing on the psychological well-being of HCWs in future outbreaks by providing them a supportive workplace is important. Increased attention should be given to the HCWs who are in direct contact with the affected patients [35]. It is important to provide tailored mental health support to the 
HCWs by considering the amount of stress that they experience. This could be done through the establishment of psychological support groups nationwide, observance of trajectory changes post-pandemic in their mental health condition, and avoiding occurrence of psychiatric disorders. One of the previous studies showed that failure to maintain the psychological well-being of the HCWs would result in increased social and economic burden in the long term [36]. Therefore, there is need to adopt appropriate intervention measures to maintain psychological well-being of the HCWs through timely screening, counselling, creation of a friendly environment, and developing positive coping strategies.

Although the present study has increased knowledge about maintaining psychological well-being of the HCWs, there are several limitations to this study. For instance, the assessment of anxiety symptoms using cut-off values are not accurate as suggested in earlier studies because this is the first study using PHQ-9 and GAD-7 among Saudi HCWs. The study has not performed multivariate analysis, which is a more complicated validation analysis with the inclusion of confirmatory factor analysis (CFA). There is a need to be cautious about making causal relationships without any further follow-up since the crosssectional study was conducted during the COVID-19 outbreak. However, the present study has provided valuable information about the psychological health of the HCWs in Saudi Arabia during COVID-19, despite these few limitations.

\section{Conclusions}

The study showed increased prevalence of adverse psychological symptoms among the HCWs in Saudi Arabia during the COVID-19 outbreak. Therefore, screening of anxiety and stress among HCWs would help in the identification of post-traumatic stress following the disease outbreak. The main threats experienced by these workers were risk of getting infected, overwhelming workload, stigmatization, and lack of necessary medical supplies. The main risk factors associated with the development of adverse psychological outcomes were maladaptive coping strategies and lack of social support. The negative psychological outcomes could be decreased by preventing early traumatic stress among the HCWs through mitigation strategies and preventive measures. There is also a need for proper screening for adverse psychological outcomes to decrease the negative psychological outcomes of the COVID-19 pandemic among HCWs. Future studies are warranted to scale up to a larger population and to evaluate the effectiveness and feasibility of these interventions.

Author Contributions: Conceptualization, H.S.A.; Formal analysis, H.S.A.; Funding acquisition, A.A. (Abdullah Alsabaani); Investigation, H.S.A.; Methodology, H.S.A., W.F.M., A.A. (Abdullah Algarni), S.F.M., A.A.B., N.N.A., R.T.M., A.M.A., A.A.G. and A.A.A.; Project administration, H.S.A.; Writing-original draft, H.S.A., W.F.M., A.A. (Abdullah Algarni), S.F.M., A.A.B., N.N.A., R.T.M., A.M.A., A.A.G. and A.A.A.; Writing-review \& editing, A.A. (Awad Alsamghan), H.S.A. and A.A. (Abdullah Alsabaani). All authors have read and agreed to the published version of the manuscript.

Funding: This work was supported by the Institute of Research and Counselling Studies at King Khalid University, Abha, Saudi Arabia (grant number \#4-N-20/21).

Institutional Review Board Statement: The study was conducted according to the guidelines of the Declaration of Helsinki, and approved by King Khalid University Research Ethics Committee (approval number: ECM\#2020-237-HAPO-06-B-001) and the Research Ethical Committee at General Di-rectorate of Health Affairs-Aseer Region, Saudi Arabia.

Informed Consent Statement: Informed consent was obtained from all subjects involved in the study.

Data Availability Statement: The data set used and analyzed during the study is available from the corresponding author upon reasonable request.

Acknowledgments: The authors are thankful to the Institute of Research and Consulting Studies at King Khalid University for supporting this research through grant number \#4-N-20/21.

Conflicts of Interest: The authors declare no conflict of interest. 


\section{References}

1. WHO. Situation Report-101 of Coronavirus Disease 2019 (COVID-19). Available online: https:/ /www.who.int/docs/defaultsource/coronaviruse/situation-reports /20200430-sitrep-101-covid-19.pdf (accessed on 30 April 2020).

2. Brooks, S.K.; Webster, R.K.; Smith, L.E.; Woodland, L.; Wessely, S.; Greenberg, N.; Rubin, G.J. The psychological impact of quarantine and how to reduce it: Rapid review of the evidence. Lancet 2020, 395, 912-920. [CrossRef]

3. Lee, S.M.; Kang, W.S.; Cho, A.R.; Kim, T.; Park, J.K. Psychological impact of the 2015 MERS outbreak on hospital workers and quarantined hemodialysis patients. Compr. Psychiatry 2018, 87, 123-127. [CrossRef] [PubMed]

4. Raven, J.; Wurie, H.; Witter, S. Health workers' experiences of coping with the Ebola epidemic in Sierra Leone's health system: A qualitative study. BMC Health Serv. Res. 2018, 18, 251. [CrossRef] [PubMed]

5. Tam, C.W.; Pang, E.P.; Lam, L.C.; Chiu, H.F. Severe acute respiratory syndrome (SARS) in Hong Kong in 2003: Stress and psychological impact among frontline healthcare workers. Psychol. Med. 2004, 34, 1197-1204. [CrossRef]

6. Si, M.Y.; Su, X.Y.; Jiang, Y.; Wang, W.J.; Gu, X.F.; Ma, L.; Li, J.; Zhang, S.K.; Ren, Z.F.; Ren, R.; et al. Psychological impact of COVID-19 on medical care workers in China. Infect. Dis. Poverty 2020, 9, 113. [CrossRef]

7. Jalloh, M.F.; Li, W.; Bunnell, R.E.; Ethier, K.A.; O’Leary, A.; Hageman, K.M.; Sengeh, P.; Jalloh, M.B.; Morgan, O.; Hersey, S.; et al. Impact of Ebola experiences and risk perceptions on mental health in Sierra Leone, July 2015. BMJ Glob. Health 2018, 3, e000471. [CrossRef]

8. Ahmadian, A.; Mirzaee, J.; Omidbeygi, M.; Holsboer-Trachsler, E.; Brand, S. Differences in maladaptive schemas between patients suffering from chronic and acute posttraumatic stress disorder and healthy controls. Neuropsychiatr. Dis. Treat. 2015, 11, 1677-1684.

9. Meli, L.; Birk, J.; Edmondson, D.; Bonanno, G.A. Trajectories of posttraumatic stress in patients with confirmed and rule-out acute coronary syndrome. Gen. Hosp. Psychiatry 2020, 62, 37-42. [CrossRef]

10. Bhagavathula, A.S.; Aldhaleei, W.A.; Rahmani, J.; Mahabadi, M.A.; Bandari, D.K. Knowledge and perceptions of COVID-19 among health care workers: Cross-sectional study. JMIR Public Health Surveill. 2020, 6, e19160. [CrossRef]

11. Lancee, W.J.; Maunder, R.G.; Goldbloom, D.S. Prevalence of psychiatric disorders among Toronto hospital workers one to two years after the SARS outbreak. Psychiatr. Serv. 2008, 59, 91-95. [CrossRef]

12. Ranieri, J.; Guerra, F.; Giacomo, D.D. Predictive risk factors for post-traumatic stress symptoms among nurses during the Italian acute COVID-19 outbreak. Health Psychol. Report 2021, 9, 180-185. [CrossRef]

13. Bai, Y.; Lin, C.C.; Lin, C.Y.; Chen, J.Y.; Chue, C.M.; Chou, P. Survey of stress reactions among health care workers involved with the SARS outbreak. Psychiatr. Serv. 2004, 55, 1055-1557. [CrossRef]

14. Bryant, R.A. Acute stress disorder as a predictor of posttraumatic stress disorder: A systematic review. J. Clin. Psychiatry 2011, 72, 233-239. [CrossRef]

15. Ranieri, J.; Guerra, F.; Perilli, E.; Passafiume, D.; Maccarone, D.; Ferri, C.; di Giacomo, D. Prolonged COVID 19 Outbreak and Psychological Response of Nurses in Italian Healthcare System: Cross-Sectional Study. Front. Psychol. 2021, 12, 608413. [CrossRef]

16. AlHadi, A.N.; AlAteeq, D.A.; Al-Sharif, E.; Bawazeer, H.M.; Alanazi, H.; AlShomrani, A.T.; Shuqdar, R.M.; AlOwaybil, R. An arabic translation, reliability, and validation of Patient Health Questionnaire in a Saudi sample. Ann. Gen. Psychiatry 2017, 16, 32 [CrossRef]

17. Kroenke, K.; Spitzer, R.L.; Williams, J.B. The PHQ-9: Validity of a brief depression severity measure. J. Gen. Intern. Med. 2001, 16, 606-613. [CrossRef]

18. Cameron, I.M.; Crawford, J.R.; Lawton, K.; Reid, I.C. Psychometric comparison of PHQ-9 and HADS for measuring depression severity in primary care. Br. J. Gen. Pract. 2008, 58, 32-36. [CrossRef]

19. Rutter, L.A.; Brown, T.A. Psychometric Properties of the Generalized Anxiety Disorder Scale-7 (GAD-7) in Outpatients with Anxiety and Mood Disorders. J. Psychopathol. Behav. Assess. 2017, 39, 140-146. [CrossRef]

20. Spitzer, R.L.; Kroenke, K.; Williams, J.B.; Löwe, B. A brief measure for assessing generalized anxiety disorder: The GAD-7. Arch Intern. Med. 2006, 166, 1092-1097. [CrossRef]

21. Wu, P.; Fang, Y.; Guan, Z.; Fan, B.; Kong, J.; Yao, Z.; Liu, X.; Fuller, C.J.; Susser, E.; Lu, J.; et al. The psychological impact of the SARS epidemic on hospital employees in China: Exposure, risk perception, and altruistic acceptance of risk. Can. J. Psychiatry 2009, 54, 302-311. [CrossRef]

22. Chew, N.W.S.; Lee, G.K.H.; Tan, B.Y.Q.; Jing, M.; Goh, Y.; Ngiam, N.J.H.; Yeo, L.L.L.; Ahmad, A.; Shanmugam, G.N.; Sharma, A.K.; et al. A multinational, multicentre study on the psychological outcomes and associated physical symptoms amongst healthcare workers during COVID-19 outbreak. Brain Behav. Immun. 2020, 88, 559-565. [CrossRef]

23. Liu, S.; Yang, L.; Zhang, C.; Xiang, Y.T.; Liu, Z.; Hu, S.; Zhang, B. Online mental health services in China during the COVID-19 outbreak. Lancet Psychiatry 2020, 7, e17-e18. [CrossRef]

24. Astill Wright, L.; Sijbrandij, M.; Sinnerton, R.; Lewis, C.; Roberts, N.P.; Bisson, J.I. Pharmacological prevention and early treatment of post-traumatic stress disorder and acute stress disorder: A systematic review and meta-analysis. Transl. Psychiatry 2019, 9, 334. [CrossRef]

25. Wu, P.; Liu, X.; Fang, Y.; Fan, B.; Fuller, C.J.; Guan, Z.; Yao, Z.; Kong, J.; Lu, J.; Litvak, I.J. Alcohol abuse/dependence symptoms among hospital employees exposed to a SARS outbreak. Alcohol Alcohol. 2008, 43, 706-712. [CrossRef]

26. Bao, Y.; Sun, Y.; Meng, S.; Shi, J.; Lu, L. 2019-nCoV epidemic: Address mental health care to empower society. Lancet 2020, 395, e37-e38. [CrossRef] 
27. Li, X.; Guan, L.; Chang, H.; Zhang, B. Core self-evaluation and burnout among Nurses: The mediating role of coping styles. PLoS ONE 2014, 9, e115799. [CrossRef]

28. Chen, Q.; Liang, M.; Li, Y.; Guo, J.; Fei, D.; Wang, L.; He, L.; Sheng, C.; Cai, Y.; Li, X.; et al. Mental health care for medical staff in China during the COVID-19 outbreak. Lancet Psychiatry 2020, 7, e15-e16. [CrossRef]

29. Dein, I.; Loewenthal, K.; Lewis, C.A.; Pargament, K.I. COVID-19, mental health and religion: An agenda for future research. Ment. Health Relig. Cult. 2020, 23, 1-9. [CrossRef]

30. Pappa, S.; Ntella, V.; Giannakas, T.; Giannakoulis, V.G.; Papoutsi, E.; Katsaounou, P. Prevalence of depression, anxiety, and insomnia among healthcare workers during the COVID-19 pandemic: A systematic review and meta-analysis. Brain Behav. Immun. 2020, 88, 901-907. [CrossRef] [PubMed]

31. Sarma, R.; Vig, S.; Rathore, P.; Pushpam, D.; Mishra, S.; Gupta, N.; Garg, R.; Kumar, V.; Bharati, S.J.; Bhatnagar, S. Concerns of Health Care Professionals Managing non-COVID Patients during the COVID-19 Pandemic: A Descriptive Cross-Sectional Study. Indian J. Palliat. Care 2020, 26, S21-S26. [PubMed]

32. Koinis, A.; Giannou, V.; Drantaki, V.; Angelaina, S.; Stratou, E.; Saridi, M. The Impact of Healthcare Workers Job Environment on Their Mental-emotional Health. Coping Strategies: The Case of a Local General Hospital. Health Psychol. Res. 2015, 3, 1984. [CrossRef]

33. Shanafelt, T.; Ripp, J.; Trockel, M. Understanding and Addressing Sources of Anxiety Among Health Care Professionals During the COVID-19 Pandemic. JAMA 2020, 323, 2133-2134. [CrossRef]

34. Maunder, R.; Hunter, J.; Vincent, L.; Bennett, J.; Peladeau, N.; Leszcz, M.; Sadavoy, J.; Verhaeghe, L.M.; Steinberg, R.; Mazzulli, T. The immediate psychological and occupational impact of the 2003 SARS outbreak in a teaching hospital. CMAJ 2003, 168, 1245-1251.

35. Brooks, S.K.; Dunn, R.; Amlôt, R.; Rubin, G.J.; Greenberg, N. A Systematic, Thematic Review of Social and Occupational Factors Associated with Psychological Outcomes in Healthcare Employees During an Infectious Disease Outbreak. J. Occup. Environ. Med. 2018, 60, 248-257. [CrossRef]

36. Sani, G.; Janiri, D.; Di Nicola, M.; Janiri, L.; Ferretti, S.; Chieffo, D. Mental health during and after the COVID-19 emergency in Italy. Psychiatry Clin. Neurosci. 2020, 74, 372. [CrossRef] 